\title{
Mesenchymal Stem Cells for Anti-Cancer Drug Delivery
}

\author{
Darinka Gjorgieva $^{1}$, Nathan Zaidman ${ }^{2}$ and Darko Bosnakovski ${ }^{1, *}$ \\ ${ }^{1}$ Faculty of Medical Sciences, University Goce Delcev, Stip, 2000, R. Macedonia; ${ }^{2}$ Department of Medicine, University \\ of Minnesota, Minneapolis, MN 55455, USA
}

Received: March 19, 2013; Accepted: April 25, 2013; Revised: May 14, 2013

\begin{abstract}
Self renewal, extensive proliferation and multilineage differentiation ability in vitro and in vivo make mesenchymal stem cells (MSCs) powerful tools for tissue engineering. Beyond their potential uses in regenerative medicine, an emerging field of research aims to utilize MSCs for anti-cancer treatment. These strategies are based on the remarkable ability of MSCs to localize and integrate into tumor stroma and deliver anti-cancer agents (US20100055167, US20120207725, US20120010499). Genetically engineered MSCs can specifically target different tumor types and locally secrete therapeutic proteins such as interferons $\alpha$ and $\beta$, interleukins 2 and 12 or chemokine $\mathrm{CX}_{3} \mathrm{CL} 1$ (US20110027239, US20120087901, WO2012071527). In addition, MSCs have also been engineered to deliver oncolytic viruses, for targeted chemotherapy using enzyme prodrug conversion or for inducing tumor cell apoptosis by delivering tumor necrosis factor-related apoptosis inducing ligand (TRAIL) (WO2012106281). The patent databases FPO and Delphion were used to locate patents that were published between 2005 and 2013. Here, we present the current progress and the most recent patents on MSC anti-cancer drug delivery systems and discuss future directions in the field.
\end{abstract}

Keywords: Cancer therapy, drug delivery, mesenchymal stem cells.

\section{INTRODUCTION}

One of the many challenges of cancer treatment concerns the delivery of anticancer drugs to the site of the tumor. Bone marrow-derived stem cells (BMSCs) have the ability to migrate specifically to, and incorporate within tumors, which makes them a potentially exciting drug delivery tool [1].

The BMSCs include two groups of cells: haematopoietic progenitor stem cells (HSCs) and mesenchymal stem cells (MSCs) [2]. The International Society for Cellular Therapy has recommended minimum criteria based on cell adherent properties, surface markers and differentiation potential for defining multi-potent human MSCs (Table 1) [3, 4].

The MSC characteristics of extensive proliferation, selfrenewal and multilineage differentiation make them a promising tool for tissue engineering and regenerative medicine [5-9]. During both proliferation and differentiation, MSCs interact with other cells through both cell-cell interactions and paracrine signaling, involving the secretion of growth factors, cytokines, antifibrotic or angiogenic mediators [10, 11].

Primary MSC targets are regions of new stroma formation including sites of hematopoiesis, inflammation, and injury. Interestingly, MSC localization and persistence in solid tumor stromal tissue have also been reported [12-16]. Furthermore, exogenously delivered MSCs' are also

\footnotetext{
*Address correspondence to this author at the Faculty of Medical Sciences, University "Goce Delcev" Stip, Krste Misirkov bb, 2000 Stip, R. Macedonia; Tel: 389 (0)70 516649; E-mail: darko.bosnakovski@ugd.edu.mk
}

preferentially locallized to tumors. These tumor tropism abilities make MSCs a suitable tool for tumor therapy as delivery vehicles for various biological agents $[17,18]$. Numerous in vivo studies using animal tumor models have shown that these cells preferentially migrate to tumors. Regardless of delivery methods (intravenously [19-24], intraperitoneal [25] or intracerebral [20]) MSCs predictably migrate, incorporate, and survive in cancer tissue. One explanation is that MSCs have a variety of surface chemokine and cytokine receptors that respond functionally to a large array of molecules that are secreted by tumors [16, 26, 27].

In several studies, immunoregulatory and proliferative effects of MSCs on tumor growth were investigated leading to two main mechanisms that are likely involved in the enhancement of tumor growth by MSCs. First, cell-to-cell cross talk between MSCs and tumor cells contribute to tumor progression [28, 29], and second, the suppressive effects of MSCs on the immune system facilitate tumor genesis, as shown for the inhibition of melanoma rejection, possibly mediated by regulatory $\mathrm{CD} 8^{+} \mathrm{T}$ cells $[15,30]$.

The ability of MSCs to migrate specifically to tumors has led several groups to engage them for delivering anticancer agents (Table 2). There are numerous studies reporting engineered MSCs specifically targeting different tumor types followed by local secretion of therapeutic proteins, such as interferon $\alpha(\operatorname{IFN} \alpha)[31,32]$ and $\beta$ (IFN $\beta)[17,20,23,31$, 32], immunostimulatory interleukin (IL)12 [33], immunomodulatory cytokine IL2 [34] or chemokine $\mathrm{CX}_{3} \mathrm{CL} 1$ (fractalkine) [22]. MSCs have also been engineered to deliver conditional replicative oncolytic viruses to reduce tumor 
Table 1. Criteria for Defining Multi-Potent Human MSCs.

\begin{tabular}{|c|c|c|}
\hline Criteria & \multicolumn{2}{|c|}{ Description } \\
\hline \hline Criterion I & \multicolumn{2}{|c|}{ Cells being adherent to plastic under standard culture conditions } \\
\hline Criterion II & Positive for the expression of: & Negative for the expression of: \\
& CD105 CD34, & CD45, \\
\cline { 2 - 3 } & CD73 & CD11a, \\
& and CD90 & CD79a, \\
& & CD14, \\
& & CD11b \\
& & and histocompatibility locus antigen (HLA)-DR \\
\hline \multirow{2}{*}{ Criterion III } & Under a specific stimulus, MSCs differentiate into osteocytes, adipocytes and chondrocytes both in vitro and in vivo. \\
\hline
\end{tabular}

Table 2. MSCs as Anticancer Drug Delivery Systems.

\begin{tabular}{|c|c|c|c|}
\hline Anticancer Agent & Effect & References & Experimental Model \\
\hline Interferon $\beta$ (IFN $\beta)$ & $\begin{array}{l}\text { Therapeutic protein, apoptosis, decreased } \\
\text { tumor mass and increased animal survival }\end{array}$ & {$[17,20,23,31,32]$} & $\begin{array}{l}\text { Gliomas, mouse prostate cancer, lung metas- } \\
\text { tasis model, pancreatic tumors }\end{array}$ \\
\hline Interferon $\alpha($ IFNa $)$ & Therapeutic protein, immunostimulatory & {$[31]$} & Mouse melanoma lung metastasis model \\
\hline Interleukin (IL)12 & Immunostimulatory & {$[33,48,49]$} & Lung and breast cancer \\
\hline Chemokine $\mathrm{CX}_{3} \mathrm{CL1}$ & Activates T cells and NK cells & {$[22]$} & Metastatic cancer \\
\hline Replicative oncolytic viruses & Reduce tumor growth and spread in vivo & {$[25,36,37]$} & Lung and breast tumor models, metastatic cancer \\
\hline $\begin{array}{l}\text { Cytoreagents for gene therapy and } \\
\text { targeted chemotherapy }\end{array}$ & Enzyme prodrug conversion & {$[38,39,40,41,42,43]$} & $\begin{array}{l}\text { Mice melanoma, human glioblastoma cells, } \\
\text { pancreatic carcinoma, colon tumors }\end{array}$ \\
\hline
\end{tabular}

growth and metastasis in vivo [25, 35-37]. Furthermore, MSCs serve as therapeutic cytoreagents for gene therapy as well as vehicles for targeted chemotherapy with an enzyme prodrug conversion [38-43]. Strong antitumor effects have been reported following administration of gene modified MSCs expressing tumor necrosis factor-related apoptosis inducing ligand (TRAIL) [19, 44-47]. In experimental cancer models, TRAIL was found to cause apoptosis selectively in glioma and lung cancer, while sparing non-cancer cells. Also, MSCs secreting IL-12 [33, 48, 49] or IL-2 [34, 50] were shown to initiate an immunoreaction and stimulate inflammatory cell infiltration in the tumor tissue but did not cause systemic toxicity [49].

MSCs can be isolated from adult tissues, including bone, fat, skeletal muscle, synovium, dental pulp, and fetal tissues, including umbilical cord blood, placenta, amniotic membranes and fluid, and Wharton's jelly [8, 29]. Although, MSCs derived from different sources share many traits, they differ in several aspects of gene expression and physiology
[29], leading some to view the proposed use of MSCs in cancer therapies as dangerous. New facts about MSC promotion of tumor vascularization and growth have been reported and are discussed later in this text.

\section{RECENT PATENTS RELATING TO MSCS AND THEIR USE AS ANTICANCER DRUG DELIVERY SYSTEMS}

It is especially important to consider the role of MSCs in the context of their immunosuppressive, reparative and angiogenic properties in specific cancer types. A further concern of the use of these cells as an anticancer delivery agent is the potential for malignant change, particularly in view of their capacity for proliferation.

In a patent published in 2006 by Furcht et al., methods for isolation of multipotent adult stem cells and its use for treating cancer are described. MSCs were genetically altered to express a tumoricidal protein, an anti-angiogenic protein, 
or a protein expressed on the surface of a tumor cell in conjunction with a protein associated with stimulation of an immune response to an antigen. In this invention, MSCs were promoted as a novel vehicle for cancer therapies that can be induced to differentiate to form endothelial cells or precursors which will home to endothelial tissues when delivered either locally or systemically. The cells participate in angiogenesis by integrating into the blood vessels in the newly-formed tumors. Upon stimulation, genetically engineered cells undergo apoptosis and the newly-formed blood vessels can be disrupted and thus blood flow to the tumor can be eliminated [51]. An example of an externallydelivered element would be the transfection/transduction of a gene that promotes apoptosis under control of a tetracycline response promoter [52]. In this system, the target gene can be activated by administration of doxycyline [52-54]. In 2010 , the same group published another invention that described genetically modified MSCs that secrete products into the extracellular environment which are toxic to tumor cells or disrupt angiogenesis, such as pigment epithelium-derived factor (PEDF) [55]. Another approach is to utilize MSCs as a vector for delivering cancer vaccines. MSCs can be isolated from the patient, cultured ex vivo, genetically modified to express the appropriate antigens, and reintroduced into the subject to produce an immune response specific to the receptors expressed on the tumor cells.

The use of MSCs and a demonstration of their various applications are given by Pittenger and Aggarwal in a patent published in 2011 [56]. The explained methods are for treating autoimmune disease, promoting wound healing, and inducing angiogenesis in tissues and organs (Table 3). The authors have examined the interactions of MSCs with isolated immune cells, including dendritic cells (DC1 and DC2), effector T-cells (Th1 and Th2), and NK cells. They discovered that MSCs may regulate the production of various factors that could regulate several steps in the immune response. These findings may be employed in the treatment of disease conditions and disorders, including autoimmune diseases, allergies, arthritis, inflamed wounds, alopecia areata, and periodontal diseases. In addition, it is believed that MSCs stimulate peripheral blood mononuclear cells (PBMCs) to produce vascular endothelial growth factor, which stimulate the formation of new blood vessels. Furthermore, it is believed that MSCs stimulate DCs to produce IFN $\beta$, which promotes tumor suppression.

In another example, methods for stem cell therapy using direct inhibitors of lysophosphatidic acid (LPA) were provided [57]. Application of MSCs in two therapeutic areas (oncology and immune and inflammatory diseases) were also of interest in the recently published patent [58]. The authors aim to avoid a central problem in adult stem therapy, namely the inability to predict the behavior of transplanted cells in a patient's body. One of the concerns is the purity of cells and the potential to transplant cell populations that already have been differentiated which may not act in the intended manner. Here, methods for stimulating and isolating MSCs have been described. Stimulated MSCs (MSC1) compared to nonstimulated MSCs (MSC2) demonstrated elevated secretion of IL4, IL6, IL8 and IL10, CXCL5, reduced secretion of transforming growth factor (TGF) $\beta 1$ and TGF $\beta 3$ and increased indoleamine 2,3-dioxygenase activity. In one em- bodiment, a method for treating ovarian cancer is provided by delivering isolated MSC incubated with at least one selected Toll-like receptor ligand (TLR) for up to $2 \mathrm{~h}$, where in vitro studies show divergent effect of MSC1 and MSC2 on co-cultures of different human cancer cell lines with MSC1 and MSC2 [58].

TGF $\beta$ is also of interest in another invention that describes effective treatment of autoimmune diseases by TGFß-incorporated MSCs [59]. According to a present disclosure, the authors provide a composition for treatment of autoimmune diseases including TGF $\beta$-encoding MSCs introduced with TGF $\beta$-encoding nucleotide sequence and a pharmaceutically suitable carrier. The composition may be administered to the organism by any known method, for example, orally or non-orally.

A new approach for targeting brain tumor cells has been developed using stem cells to deliver therapeutic agents to tumor areas. For targeted delivery, neural stem cells (NSCs) have been well studied and applied first. For example, a group of authors have demonstrated that neural stem cells (NSCs) possess significant migratory behavior with extensive tropism to gliomas when administered intracranial [6063]. NSCs distribute throughout the primary tumor and migrate together with widely outgrowing tumor microsatellites. Moreover, when NSCs are implanted intracranial at sites distant from the tumor, they migrate through the normal parenchyma and localize in the tumor. This behavior of NSCs has been exploited as a tumor-targeting strategy for glioma gene therapy [42, 60-63].

The new invention, presented by Zhang et al. published in 2010 [64], provided technology for treatments of central nervous system (CNS) tumors with stem cells (Table 3). Briefly, the disclosure provides a modified stem cell controlled-release vehicle with anti-neoplastic agent. A controlled-release vehicle is selected from a group consisting of nanoparticles, biocompatible polymers, polymeric matrices, liposomes and lipospheres. The modified stem cells exhibit tropism to glioma cells, leading to a locally-concentrated dose of the anti-neoplastic agent which may kill or damage the target cells or tissues, resulting in destruction of the tumor seen by reduction of the tumor size or volume. The modified stem cells may be administered after surgery, or to patients that for one or more reasons has not and/or cannot undergo surgery or conventional radiotherapy or chemotherapy. In addition, for more effective therapy the modified stem cells may be loaded with more than one chemotherapeutic agent for targeting neoplastic cells.

The use of magnetic nanoparticles for labeling MSCs in cancer treatment is given in a recently published invention by Janes et al. [65]. The authors developed a new technique that utilized MRI to track MSCs labeled with biocompatible iron oxide nanoparticles. They suggested that labeled-MSCs can be used for the delivery of anti-tumor factors directly to the site of tumors. Furthermore, the iron oxide nanoparticles incorporated into the MSCs can also be used to damage the tumor by thermotherapy.

An interesting approach given in the invention of Deng et $a l$, is a combined use of MSCs and protein vaccine for treating cancer (Table 3) [66, 67]. The authors present a 
Table 3. Patents Subjected to MSCs and their Use.

\begin{tabular}{|c|c|c|c|}
\hline Patent/Year & Inventor(s) & Reference & Description of the Invention \\
\hline $\begin{array}{l}\text { US7015037 } \\
(2006)\end{array}$ & $\begin{array}{l}\text { Furcht, L.T, Verfaillie, C.M., } \\
\text { Reyes, M. }\end{array}$ & [51] & $\begin{array}{l}\text { MASCs isolation methods and MASCs as a novel vehicle } \\
\text { for cancer therapies. }\end{array}$ \\
\hline $\begin{array}{l}\text { US7659118 } \\
(2010)\end{array}$ & $\begin{array}{l}\text { Furcht, L.T., Verfaillie, C.M., } \\
\text { Reyes, M. }\end{array}$ & [55] & Genetically altered MASCs toxic to tumor cells. \\
\hline $\begin{array}{l}\text { US20110142807 } \\
\qquad(2011)\end{array}$ & Pittenger, M.E., Aggarwal, S. & [56] & $\begin{array}{l}\text { MSC for treating autoimmune disease, promoting wound } \\
\text { healing, and promoting angiogenesis. }\end{array}$ \\
\hline $\begin{array}{l}\text { US20100055167 } \\
\quad(2010)\end{array}$ & Zhang, A., Guan, Y., Chen, L. & [64] & $\begin{array}{l}\text { Modified stem cells may be loaded with one or more } \\
\text { chemotherapeutic agents for targeting neoplastic cell. }\end{array}$ \\
\hline $\begin{array}{l}\text { US } 20110027311 \\
(2011)\end{array}$ & $\begin{array}{l}\text { Deng, W-P., Chang, H-K., Wei, } \\
\text { H-C., Wu, T-H.A. }\end{array}$ & [66] & $\begin{array}{l}\text { Combination of protein vaccine and MSC (encoding at } \\
\text { least one oncogenic protein) for treating cancer. }\end{array}$ \\
\hline $\begin{array}{l}\text { WO2012051210 } \\
\text { (2012) }\end{array}$ & Betancourt, A.M. & [58] & MSCs and related therapies \\
\hline $\begin{array}{l}\text { US20120207725 } \\
\text { (2012) }\end{array}$ & $\begin{array}{l}\text { Cho, S.G., Park, M.J., Park, } \\
\text { H.S, Cho, M.L. }\end{array}$ & [59] & $\begin{array}{l}\text { Uses of MSCs incorporated with TGF } \beta \text { nucleotide } \\
\text { sequence }\end{array}$ \\
\hline $\begin{array}{l}\text { US20120010499 } \\
\text { (2012) }\end{array}$ & $\begin{array}{l}\text { Janes, S.M., Lythgoe, M.F., } \\
\text { Pankhurst, Q. }\end{array}$ & [65] & $\begin{array}{l}\text { Uses of MSCs incorporated with nanoparticles for cancer } \\
\text { treatment }\end{array}$ \\
\hline $\begin{array}{l}\text { US20130052272 } \\
\text { (2013) }\end{array}$ & Cohen, S. & [68] & $\begin{array}{l}\text { Uses of cell extracts for treatment and prevention of } \\
\text { cancer. }\end{array}$ \\
\hline $\begin{array}{l}\text { WO2013023040 } \\
\quad(2013)\end{array}$ & Sabbadini, R.A. & [57] & Stem cell therapy using inhibitors of LPA \\
\hline
\end{tabular}

method based on administration of a mammal-effective amount of stem cells encoding an oncogenic protein and a vaccine composition of immunogenic protein capable of eliciting an antibody specific effect against the oncogenic protein. Cancer vaccine therapy appears to be an attractive approach for cancer treatment because it has potential to target systemic tumors at multiple sites and specificity to distinguish healthy cells from neoplastic one.

Cancer can be initiated from epigenetic and genetic alterations of the genome presented as activation of oncogenes and inactivation of tumor-suppressor genes. The epigenetic alterations manifest as cell proliferation, inhibition of apoptosis and induction of angiogenesis. Whether a cell will obtain a malignant phenotype or not depends on differentiation state and epigenetic conformation. A recently published invention explains pharmaceutical compositions and methods for treatment of proliferative diseases such as cancer. The present invention is based on the fact that intra- and extracellular components of cells, particular stem cells, can serve as a rich source of biomolecules. These biomolecules can be growth factors, cytokines, structural elements and transcription factors, which can be involved in epigenetic reprogramming, or act to alter or reverse the malignant nature of the cancer cell and tissues [68].

\section{MSCS GENETICALLY MODIFIED TO EXPRESS A SUICIDE GENE FOR TREATING A CANCER}

MSCs expressing a suicide gene show excellent and highly selective anticancer effects. The method is based on selective conversion of a prodrug to an anticancer agent at the site of the cancer. Suicide genes are capable of converting a non-toxic prodrug to corresponding anticancer drug. For example, cytosine deaminase (CD) can convert 5fluorocytosine (5-FC) to cytotoxic 5-fluorouracil (5-FU) which kills neighboring cells (bystander effect). The direct administration of 5-FU cause's cytotoxicity and leads to adverse side effects, but combination of a suicidal gene and 5FC makes it possible to generate 5-FU selectively around tumor cells [69, 70]. Another example of a suicide gene is encoding herpes simplex type 1 thymidine kinase (HSVTK), which converts non-toxic gancyclovir into a toxic phosphorylated metabolite [38]. Patents published in 2010 and 2012 by Nelson [71], provide a method for treating patients with pancreatic cancer through introducing a therapeutically effective number of genetically modified MSCs by IV. Engineered MSCs can selectively express cytotoxic protein when they come into proximity of the tumor's stromal tissue. Briefly, the patents provide a method for treating pancreatic tumor in human subjects by CD34 modified cells with herpes simplex viral thymidine kinase encoding region operable linked to a RANTES promoter. The method first introduces about $1 \times 10^{5}$ to $1 \times 10^{9}$ cells $/ \mathrm{kg}$ body weight of genetically modified CD34 stem cells into the patient's blood followed by gancyclovir in a manner permitting the herpes simplex viral thymidine kinase to render the gancyclovir cytotoxic.

The patent published in 2005 by Snyder et al. [72] relates to treatments of CNS tumors with modified and unmodified stem cells (Table 4). Particularly, the method explains systemic treatment of CNS and other tumors using NSCs which, 
Table 4. Patents Subjected to MSCs Genetically Modified to Express a Suicide Gene.

\begin{tabular}{|c|c|c|l|}
\hline Patent/Year & Inventor(s) & Reference & \multicolumn{1}{|c|}{ Description of the invention } \\
\hline \hline $\begin{array}{c}\text { US20050019313 } \\
(\mathbf{2 0 0 5 )}\end{array}$ & $\begin{array}{c}\text { Snyder, E.Y., Aboody, K.S., } \\
\text { Brown, A.B., Breakefield, X.O. }\end{array}$ & {$[72]$} & Method of systemic treatment of CNS and other tumors. \\
\hline $\begin{array}{c}\text { US20080241115 } \\
(\mathbf{2 0 0 8 )}\end{array}$ & $\begin{array}{c}\text { Suh, H-Y., Chang, D-Y., Kim, } \\
\text { S-S., Yoo, S-W., Lee, Y-D. }\end{array}$ & [74] & $\begin{array}{l}\text { Provides a kit for treating a cancer comprising an expres- } \\
\text { sion vector, with suicide gene, MSC and a prodrug of an } \\
\text { anticancer agent. }\end{array}$ \\
\hline $\begin{array}{c}\text { US20090117050 } \\
(\mathbf{2 0 0 9 )}\end{array}$ & Cady, C., McAsey, M. & [75] & $\begin{array}{l}\text { Methods for detecting and treating ovarian cancer with } \\
\text { stem cells. }\end{array}$ \\
\hline $\begin{array}{c}\text { WO2010119039 } \\
(\mathbf{2 0 1 0})\end{array}$ & Nelson, P. & $\begin{array}{l}\text { Genetically engineered MSCs and method of their use to } \\
\text { treat tumors. }\end{array}$ \\
\hline $\begin{array}{c}\text { US20120087901 } \\
(\mathbf{2 0 1 2})\end{array}$ & {$[71]$} & $\begin{array}{l}\text { Engineered MSCs and methods of using them to treat } \\
\text { tumors. }\end{array}$ \\
\hline
\end{tabular}

like MSCs, fulfilled the requirement for cells with high migratory potential to the tumor and metastases site [73]. After a certain time, the stem cells migrate to the tumor site and systematically administered 5-FC would be converted by stem cells to toxic 5-FU [72].

Another study exploited safe and effective anticancer agents through expression of a suicide gene in MSCs which migrate into brain cancer in an animal model (Table 4) [74]. The authors patented a kit for cancer treatment which consists of an expression vector with a suicide gene, MSCs and a prodrug of an anticancer agent. They suggest bone marrow, peripheral blood or cord blood as a source for MSC isolation.

For the first time, stem cells have been used for detection and treatment of ovarian cancer in an invention published in 2009 by Cady and McAsey (Table 4) [75]. Their method includes administering labeled stem cells to patients having, or suspected of having, a cancer and detecting the distribution of the stem cells. In some configurations, the label can be nanoparticles like mono-crystalline iron oxide which can be detected by magnetic resonance imaging. Treatment methods include administration of stem cells hosting a therapeutic agent such as an enzyme which converts the prodrug (5-FC) into a cytotoxic metabolite.

\section{MSCS MEDIATED VIRUS DELIVERY AND DELIV- ERY OF THERAPEUTIC PROTEINS}

A significant advantage of MSCs as cellular vehicles is that they are relatively easy to genetically manipulate in $v i$ tro. In a majority of trials, adenovirus was used as a delivery vector. Low transfection efficiency using wild type adenoviruses results from the fact that MSCs have low levels of adenovirus receptor and a high-integrin phenotype. Modification of the adenovirus with incorporation of an arginine-glycineaspartate section improves MSC transduction efficiency [36, 37]. Newly generated conditionally replicating adenoviruses provides increased delivery of viral load specifically to the tumor site [25, 35, 37]. It is critically important to avoid premature toxicity to MSCs prior to engraftment at the target site. By using an adenovirus with relatively slow kinetics, one can avoid early cell death [76].
One of the difficulties in the treatment of conditions such as cancer is the need to deliver large quantities of the therapeutic agent for extended periods of time. One approach is to use MSCs as micro carriers for protein delivery [77]. The invention of Paek from 2011 is based on this theory, and describes an adipose-derived stromal cell (ASC)-based delivery system for therapeutic delivery of biologically active anti-cancer agents. Some of the suggested deliverables to the tumor mass are anti-cancer protein molecules, apoptosisinducing molecules, or an agent that inhibits the expression of an oncogene. The authors showed that ASC populations migrate and home into the cancer tissue making it possible to deliver a high dose of an anti-cancer agent locally and directly to the tumor site. In addition, ASCs have a short halflife in the circulation, so systemic non-specific responses will be minimal. This method allows the use of higher concentrations of the anti-cancer agents for more effective cancer treatment [78]. Integration of MSCs in the tumor stroma allows delivery of required dose of biological agents with short half-life or prominent toxicity. MSCs also can produce biological products at tumor sites and improve agents' pharmacokinetics [17]. One of the pioneering studies in this field is the work of Studeny et al. [79] where MSCs or stromal cell precursors were genetically modified to produce a therapeutic agent. The production of the therapeutic agent was localized in a specific area because gene modified cells preferentially localize in the target microenvironment. Exemplary microenvironments include a tumor or a wound in a tissue and/or organ. An anticancer agent includes, but is not limited to cytokines, a hormone, an enzyme, a signaling molecule, or an anti-angiogenic polypeptide. The therapeutic agent may be IFN $\alpha$, IFN $\beta$ or similar. For example, with animal tumor models it has been shown that application of MSCs expressing IFN $\beta$ resulted in decreased tumor mass and increased animal survival. This fact brings new potential to the use of MSCs for regional secretion of IFN $\beta$, because increased systemic levels of IFN $\beta$ and secretion at distant sites are not effective [20, 80]. Regional secretion is also required for a therapeutic effect of IL-12, and there are reports of significant therapeutic effect of MSCs engineered to secrete IL-12 [48]. Furthermore, MSCs secreting IL-12 [33, $48,49]$ or IL-2 $[34,50]$ were shown to initiate an immunore- 
action and stimulate inflammatory cell infiltration in the tumor tissue. Delivery of MSC-IL-12 increased tumor levels of IL-12 and did not cause systemic toxicity [49].

MSCs secreting TRAIL have been used in different models of cancers in vivo, resulting in significant anti-tumor effects $[19,46,47,65,81,82]$. On the other side, MSCs (like most healthy tissues) are resistant to TRAIL-induced apoptosis due to their low levels and/or inactive receptors [46]. In addition, in the TRAIL transfected adult mesenchymal stem cells, fetal-MSCs and umbilical cord matrix stem cells, there is almost undetectable levels of apoptotic pathway components such as caspase- 8 and -9 [83]. Delivery of this agent has advantages over some of the other anticancer MSC delivery systems described above since there appears to be very limited effects on non-cancerous tissues. Current clinical trials for TRAIL therapy in the form of recombinant protein and monoclonal antibodies show promising early results [84, 85]. However, targeted delivery of TRAIL with MSCs overcomes some of the problems which occurred in recombinant TRAIL therapy. MSC-TRAIL is more physiological than the monoclonal antibodies with much better half-life and delivery across the blood-brain barrier [1]. In an animal model study of lung cancer, local delivery of TRAIL by MSCs led to a reduction in tumor growth and significantly decreases lung metastases [19]. Also, therapeutic combination of the inhibitor of lipoxygenase MK886 and TRAIL-secreting human MSCs provided targeted and prolonged delivery of TRAIL in mouse models of glioma and in vitro [86]. The ability of TRAIL to selectively target tumor cells makes it an attractive candidate for therapy of malignant brain tumors [87]. In the invention of Shah, the methods of implantation of therapeutically engineered MSC with anti-tumor agents into tumor sites after surgery was presented. The results showed that MSC-TRAIL cytotoxic therapy is highly effective in inducing apoptosis and that TRAIL is a potent inhibitor of brain tumor growth. It was suggested that the present approach would significantly improve treatment outcomes [87].

\section{NEW CONCERNS ABOUT USE OF MSCs FOR TU- MOR TREATMENT}

Great progress has been made in the research of MSCs, which generated a significant amount of interest as a result of their ability to home to the tumor site after systemic delivery. The proposed use of MSCs in cancer therapies is controversial, however, due to MSC promotion of tumor vascularization, promotion of cancer progression and the invasive tendency of tumors have been previously reported $[29,88$, 89]. In some peritoneal cancers, like ovarian, bone delivered MSCs have been described as located around the tumor cells and in the ascitic fluid and no longer defined as multipotent as they are unable to differentiate in different cell lineages. They are defined as being carcinoma-associated (CA-MSCs) and present some characteristic markers of CarcinomaAssociated Fibroblasts (CAFs) [90]. A few authors and their research groups recently published that MSCs also can be involved in the development of chemoresistance to different chemotherapies through the release of factors in the neighborhood of tumors [91-95]. A number of targeted therapeutics are currently under development targeting not only cancer cells but also cells from the microenvironment such as endothelial cells or mesenchymal stem cells. Although, these therapeutic approaches seem promising, they carry many side effects associated with the elimination of cells not involved in cancer progression or in chemoresistance. This is only a brief overlook on this topic because there is still no evidence which supports this hypothesis, and hope still remains as many authors have described cells from the microenvironment which display several differences with their parent cells. Akimoto et al. [29] in their work isolated primary glioblastoma multiforme (GBM) cells and used MSC co-culture and co-transplantation assays to analyze characteristics. They demonstrate that Umbilical cord bloodderived MSCs (UCB-MSCs) inhibit GBM proliferative activity, whereas Adipose tissue-derived MSCs (AT-MSCs) support GBM proliferation and presents their findings that the source of MSCs is very important for their clinical application. Differences also lie between cells of the same origin but which have evolved differently depending on the organ and associated pathologies. Parental cells (such as macrophages, neutrophils or MSCs) can mostly be found with antitumoral properties. In their study, Teng et al. [96] show that DNA hypermethylation within a specific tumor suppressor gene is sufficient to fully transform a somatic mesenchymal stem cell and proposed that under the influence of different environmental niches, these transformed stem cells could give rise to tissue-specific cancers. In agreement with previous reports suggesting contradictory effects of MSCs on tumor cell proliferation [34, 38, 97], some types of MSC show tumor cell cytotoxicity, while others do not. The proliferation of some cancer cells was enhanced by adding MSCs to the culture [88, 89] while on the other hand, some groups have reported the anticancer activity of MSCs [17, 20, 23, 42, 47, 97-99]. Conventional anticancer drug screening is typically performed in the absence of accessory cells of the tumor microenvironment, which can alter antitumor activity. Preclinical drug testing in the absence of relevant tumor microenvironment interactions may explain, at least in part, the gap between preclinical and clinical efficacy in cancers [100]. The inhibitory effect of MSCs on different types of tumor proliferation should be investigated before MSCs are used as a tool for drug delivery. However, very little is known about what actually causes the switch of a cell surrounding a tumor from inhibiting tumor growth to tumorpromoting. Therefore, given the evidence this hypothesis will be challenging.

\section{CURRENT \& FUTURE DEVELOPMENTS}

A central issue in cancer chemotherapy is the severe toxic side effects of anticancer agents on healthy tissues, which invariably imposes dose reduction, treatment delay or even discontinuance of therapy. Toxicity for healthy organs can be significantly diminished by employing a drug delivery systems which targets only cancer cells. The ultimate goal of this area of research is the development of an anticancer therapy for humans and use of specific targeting to produce significantly less host toxicity than traditional agents and much higher local concentrations of antitumor agents.

Traditional chemotherapeutic agents are administered systemically. This may have undesirable side effects if the anti-cancer drug acts non-specifically on non-cancer cells, and may also result in only a small amount of the anti-cancer 
drug actually reaching the site of the tumor. Additionally, the natural process of angiogenesis which provides vascularization and nutrients to the tumor may causes a concomitant increase in the size of the tumor. In some instances an antitumor drug or chemotherapeutic agent have been directed to the site of the tumor and specifically targets cancer cells using cell-surface targeting moieties, also called tumor associated antigens. However, even these methods suffer from a lack of effectiveness as the tumor associated antigens are not necessarily ubiquitous.

Accordingly, there is a need for more targeted tumor therapies.

This review highlights the potential for MSC-mediated delivery of therapeutic agents directly to tumor tissue based on the MSCs ability to localize and integrate into the tumor stroma. There are studies reporting engineered MSCs specifically targeting different tumor types followed by local secretion of therapeutic proteins such as, IFN $\alpha$ and IFN $\beta$, IL12, IL2 or CX3CL1. MSCs have also been engineered to deliver conditional replicative oncolytic viruses. Furthermore, MSCs serve as therapeutic cytoreagents for gene therapy and vehicles for targeted chemotherapy with an enzyme prodrug conversion. Strong antitumor effects have been reported following administration of gene modified MSCs expressing TRAIL. Further understanding of the biology of MSCs, and the specific combination of factors controlling their tumour-specific migration and persistence will help these technologies translate to the clinical setting. To ensure the safety of anticancer therapy using MSCs and in agreement with previous reports suggesting contradictory effects of MSCs on tumor cell proliferation, the characteristics of MSCs themselves are quite important and should be investigated before using an MSC-based therapy.

\section{CONFLICT OF INTEREST}

The authors confirm that this article content has no conflicts of interest.

\section{ACKNOWLEDGEMENTS}

Darko Bosnakovski laboratory was partially supported by AFM (2011-205/ 15380) and "FSH Society Research Fellowship grant FSHS-82010-01”.

\section{REFERENCES}

[1] Loebinger MR, Janes SM. Stem cells as vectors for antitumour therapy. Thorax 2010; 65: 362-9.

[2] Bonnet D. Biology of human bone marrow stem cells. Clin Exp Med 2003; 3: 140-9.

[3] Dominici M, Le Blanc K, Mueller I, Slaper-Cortenbach I, Marini F, Krause D, et al. Minimal criteria for defining multipotent mesenchymal stromal cells. The International Society for Cellular Therapy position statement. Cytotherapy 2006; 8: 315-7.

[4] Horwitz EM, Le Blanc K, Dominici M, Mueller I, SlaperCortenbach I, Marini FC, et al. Clarification of the nomenclature for MSC: The International Society for Cellular Therapy position statement. Cytotherapy 2005; 7: 393-5.

[5] Fox JM, Chamberlain G, Ashton BA, Middleton J. Recent advances into the understanding of mesenchymal stem cell trafficking. Br J Haematol 2007; 137: 491-502.

[6] Picinich SC, Mishra PJ, Glod J, Banerjee D. The therapeutic potential of mesenchymal stem cells. Cell- \& tissue-based therapy. Expert Opin Biol Ther 2007; 7: 965-73.
[7] Prockop DJ. Marrow stromal cells as stem cells for nonhematopoietic tissues. Science 1997; 276: 71-4.

[8] Pittenger MF, Mackay AM, Beck SC, Jaiswal RK, Douglas R, Mosca JD, et al. Multilineage potential of adult human mesenchymal stem cells. Science 1999; 284: 143-7.

[9] Gang EJ, Bosnakovski D, Figueiredo CA, Visser JW, Perlingeiro RC. SSEA-4 identifies mesenchymal stem cells from bone marrow. Blood 2007; 109: 1743-51.

[10] Djouad F, Bouffi C, Ghannam S, Noel D, Jorgensen C. Mesenchymal stem cells: Innovative therapeutic tools for rheumatic diseases. Nat Rev Rheumatol 2009; 5: 392-9.

[11] Uccelli A, Moretta L, Pistoia V. Mesenchymal stem cells in health and disease. Nat Rev Immunol 2008; 8: 726-36.

[12] Mendes SC, Robin C, Dzierzak E. Mesenchymal progenitor cells localize within hematopoietic sites throughout ontogeny. Development 2005; 132: 1127-36.

[13] Sordi V, Malosio ML, Marchesi F, Mercalli A, Melzi R, Giordano $\mathrm{T}$, et al. Bone marrow mesenchymal stem cells express a restricted set of functionally active chemokine receptors capable of promoting migration to pancreatic islets. Blood 2005; 106: 419-27.

[14] Giordano A, Galderisi U, Marino IR. From the laboratory bench to the patient's bedside: An update on clinical trials with mesenchymal stem cells. J Cell Physiol 2007; 211: 27-35.

[15] Subramanian A, Shu-Uin G, Kae-Siang N, Gauthaman K, Biswas A, Choolani M, et al. Human umbilical cord Wharton's jelly mesenchymal stem cells do not transform to tumor-associated fibroblasts in the presence of breast and ovarian cancer cells unlike bone marrow mesenchymal stem cells. J Cell Biochem 2012; 113: 188695.

[16] Lotfi R, Eisenbacher J, Solgi G, Fuchs K, Yildiz T, Nienhaus C, et al. Human mesenchymal stem cells respond to native but not oxidized damage associated molecular pattern molecules from necrotic (tumor) material. Eur J Immunol 2011; 41: 2021-8.

[17] Studeny M, Marini FC, Champlin RE, Zompetta C, Fidler IJ, Andreeff M. Bone marrow-derived mesenchymal stem cells as vehicles for interferon-beta delivery into tumors. Cancer Res 2002; 62: 3603-8.

[18] Gao Z, Zhang L, Hu J, Sun Y. Mesenchymal stem cells: A potential targeted-delivery vehicle for anti-cancer drug, loaded nanoparticles. Nanomedicine 2013; 9: 174-84.

[19] Loebinger MR, Eddaoudi A, Davies D, Janes SM. Mesenchymal stem cell delivery of TRAIL can eliminate metastatic cancer. Cancer Res 2009; 69: 4134-42.

[20] Nakamizo A, Marini F, Amano T, Khan A, Studeny M, Gumin J, et al. Human bone marrow-derived mesenchymal stem cells in the treatment of gliomas. Cancer Res 2005; 65: 3307-18.

[21] Menon LG, Picinich S, Koneru R, Gao H, Lin SY, Koneru M, et al. Differential gene expression associated with migration of mesenchymal stem cells to conditioned medium from tumor cells or bone marrow cells. Stem Cells 2007; 25: 520-8.

[22] Xin H, Kanehira M, Mizuguchi H, Hayakawa T, Kikuchi T, Nukiwa T, et al. Targeted delivery of CX3CL1 to multiple lung tumors by mesenchymal stem cells. Stem Cells 2007; 25: 1618-26.

[23] Studeny M, Marini FC, Dembinski JL, Zompetta C, CabreiraHansen M, Bekele BN, et al. Mesenchymal stem cells: Potential precursors for tumor stroma and targeted-delivery vehicles for anticancer agents. J Natl Cancer Inst 2004; 96: 1593-603.

[24] Khakoo AY, Pati S, Anderson SA, Reid W, Elshal MF, Rovira II, et al. Human mesenchymal stem cells exert potent antitumorigenic effects in a model of Kaposi's sarcoma. J Exp Med 2006; 203: 1235-47.

[25] Komarova S, Kawakami Y, Stoff-Khalili MA, Curiel DT, Pereboeva L. Mesenchymal progenitor cells as cellular vehicles for delivery of oncolytic adenoviruses. Mol Cancer Ther 2006; 5: 755-66.

[26] Dwyer RM, Potter-Beirne SM, Harrington KA, Lowery AJ, Hennessy E, Murphy JM, et al. Monocyte chemotactic protein-1 secreted by primary breast tumors stimulates migration of mesenchymal stem cells. Clin Cancer Res 2007; 13: 5020-7.

[27] Chamberlain G, Fox J, Ashton B, Middleton J. Concise review: Mesenchymal stem cells: Their phenotype, differentiation capacity, immunological features, and potential for homing. Stem Cells 2007; 25: 2739-49.

[28] Karnoub AE, Dash AB, Vo AP, Sullivan A, Brooks MW, Bell GW, et al. Mesenchymal stem cells within tumour stroma promote breast cancer metastasis. Nature 2007; 449: 557-63. 
[29] Akimoto K, Kimura K, Nagano M, Takano S, To'a Salazar G, Yamashita $\mathrm{T}$, et al. Umbilical cord blood-derived mesenchymal stem cells inhibit, but adipose tissue-derived mesenchymal stem cells promote, glioblastoma multiforme proliferation. Stem Cells Dev 2013; 22(9): 1370-86.

[30] Djouad F, Plence P, Bony C, Tropel P, Apparailly F, Sany J, et al. Immunosuppressive effect of mesenchymal stem cells favors tumor growth in allogeneic animals. Blood 2003; 102: 3837-44.

[31] Ren C, Kumar S, Chanda D, Chen J, Mountz JD, Ponnazhagan S. Therapeutic potential of mesenchymal stem cells producing interferon-alpha in a mouse melanoma lung metastasis model. Stem Cells 2008; 26: 2332-8.

[32] Ren C, Kumar S, Chanda D, Kallman L, Chen J, Mountz JD, et al. Cancer gene therapy using mesenchymal stem cells expressing interferon-beta in a mouse prostate cancer lung metastasis model. Gene Ther 2008; 15: 1446-53.

[33] Chen XC, Wang R, Zhao X, Wei YQ, Hu M, Wang YS, et al. Prophylaxis against carcinogenesis in three kinds of unestablished tumor models via IL12-gene-engineered MSCs. Carcinogenesis 2006; 27: 2434-41.

[34] Nakamura K, Ito Y, Kawano Y, Kurozumi K, Kobune M, Tsuda H, et al. Antitumor effect of genetically engineered mesenchymal stem cells in a rat glioma model. Gene Ther 2004; 11: 1155-64.

[35] Hakkarainen T, Särkioja M, Lehenkari P, Miettinen S, Ylikomi T, Suuronen R, et al. Human mesenchymal stem cells lack tumor tropism but enhance the antitumor activity of oncolytic adenoviruses in orthotopic lung and breast tumors. Hum Gene Ther 2007; 18: 627-41.

[36] Stoff-Khalili MA, Rivera AA, Mathis JM, Banerjee NS, Moon AS, Hess A, et al. Mesenchymal stem cells as a vehicle for targeted delivery of CRAds to lung metastases of breast carcinoma. Breast Cancer Res Treat 2007; 105: 157-67.

[37] Dembinski JL, Spaeth EL, Fueyo J, Gomez-Manzano C, Studeny $\mathrm{M}$, Andreeff $\mathrm{M}$, et al. Reduction of nontarget infection and systemic toxicity by targeted delivery of conditionally replicating viruses transported in mesenchymal stem cells. Cancer Gene Ther 2010; 17: 289-97.

[38] Uchibori R, Okada T, Ito T, Urabe M, Mizukami H, Kume A, et al. Retroviral vector-producing mesenchymal stem cells for targeted suicide cancer gene therapy. J Gene Med 2009; 11: 373-81.

[39] Kucerova L, Matuskova M, Pastorakova A, Tyciakova S, Jakubikova J, Bohovic R, et al. Cytosine deaminase expressing human mesenchymal stem cells mediated tumour regression in melanoma bearing mice. J Gene Med 2008; 10: 1071-82.

[40] Matuskova M, Hlubinova K, Pastorakova A, Hunakova L, Altanerova V, Altaner C, et al. HSV-tk expressing mesenchymal stem cells exert bystander effect on human glioblastoma cells. Cancer Lett 2010; 290: 58-67.

[41] Zischek C, Niess H, Ischenko I, Conrad C, Huss R, Jauch KW, et al. Targeting tumor stroma using engineered mesenchymal stem cells reduces the growth of pancreatic carcinoma. Ann Surg 2009; 250: 747-53

[42] Hamada H, Kobune M, Nakamura K, Kawano Y, Kato K, Honmou $\mathrm{O}$, et al. Mesenchymal stem cells (MSC) as therapeutic cytoreagents for gene therapy. Cancer Sci 2005; 96: 149-56.

[43] Kucerova L, Altanerova V, Matuskova M, Tyciakova S, Altaner C. Adipose tissue-derived human mesenchymal stem cells mediated prodrug cancer gene therapy. Cancer Res 2007; 67: 6304-13.

[44] Kim SW, Kim SJ, Park SH, Yang HG, Kang MC, Choi YW, et al. Complete regression of metastatic renal cell carcinoma by multiple injections of engineered mesenchymal stem cells expressing dodecameric TRAIL and HSV-TK. Clin Cancer Res 2013; 19: 415-27.

[45] Benedetti S, Pirola B, Pollo B, Magrassi L, Bruzzone MG, Rigamonti D, et al. Gene therapy of experimental brain tumors using neural progenitor cells. Nat Med 2000; 6: 447-50.

[46] Mohr A, Lyons M, Deedigan L, Harte T, Shaw G, Howard L, et al. Mesenchymal stem cells expressing TRAIL lead to tumour growth inhibition in an experimental lung cancer model. J Cell Mol Med 2008; 12: 2628-43.

[47] Kim SM, Lim JY, Park SI, Jeong CH, Oh JH, Jeong M, et al. Gene therapy using TRAIL-secreting human umbilical cord bloodderived mesenchymal stem cells against intracranial glioma. Cancer Res 2008; 68: 9614-23.

[48] Eliopoulos N, Francois M, Boivin MN, Martineau D, Galipeau J. Neo-organoid of marrow mesenchymal stromal cells secreting in- terleukin-12 for breast cancer therapy. Cancer Res 2008; 68: 481018.

[49] Chen X, Lin X, Zhao J, Shi W, Zhang H, Wang Y, et al. A tumorselective biotherapy with prolonged impact on established metastases based on cytokine gene-engineered MSCs. Mol Ther 2008; 16 : 749-56.

[50] Stagg J, Lejeune L, Paquin A, Galipeau J. Marrow stromal cells for interleukin-2 delivery in cancer immunotherapy. Hum Gene Ther 2004; 15: 597-608.

[51] Furcht, L.T., Verfaillie, C.M., Reyes, M. Multipotent adult stem cells and methods for isolation. US7015037 (2006)

[52] Gossen M, Bujard H. Tight control of gene expression in mammalian cells by tetracycline-responsive promoters. Proc Natl Acad Sci USA 1992; 89: 5547-51.

[53] Iacovino M, Bosnakovski D, Fey H, Rux D, Bajwa G, Mahen E, et al. Inducible cassette exchange: A rapid and efficient system enabling conditional gene expression in embryonic stem and primary cells. Stem Cells 2011; 29: 1580-8.

[54] Bosnakovski D, Xu Z, Gang EJ, Galindo CL, Liu M, Simsek T, et al. An isogenetic myoblast expression screen identifies DUX4 mediated FSHD-associated molecular pathologies. EMBO J 2008; 27: 2766-79.

[55] Furcht, L.T., Verfaillie, C.M., Reyes, M. Multipotent adult stem cells. US7659118 (2010).

[56] Pittenger, M.E., Aggarwal, S. Mesenchymal stem cells and uses therefor. US20110142807 (2011).

[57] Sabbadini, R.A. Stem cell therapy using inhibitors of lysophosphatidic acid. WO2013023040 (2013).

[58] Betancourt, A.M. Mesenchymal stem cells and related therapies. WO2012051210 (2012)

[59] Cho, S.G, Park, M.J., Park, H.S, Cho, M.L. Mesenchymal stem cell incorporating a nucleotide sequence coding TGF $\beta$, and uses thereof. US20120207725 (2012).

[60] Shinojima N, Hossain A, Takezaki T, Fueyo J, Gumin J, Gao F, et al. TGF-beta mediates homing of bone marrow-derived human mesenchymal stem cells to glioma stem cells. Cancer Res 2013 73(7): 2333-44.

[61] Brown AB, Yang W, Schmidt NO, Carroll R, Leishear KK, Rainov $\mathrm{NG}$, et al. Intravascular delivery of neural stem cell lines to target intracranial and extracranial tumors of neural and non-neural origin. Hum Gene Ther 2003; 14: 1777-85.

[62] Aboody KS, Brown A, Rainov NG, Bower KA, Liu S, Yang W, et al. Neural stem cells display extensive tropism for pathology in adult brain: Evidence from intracranial gliomas. Proc Natl Acad Sci USA 2000; 97 : 12846-51.

[63] Ho IA, Toh HC, Ng WH, Teo YL, Guo CM, Hui KM, et al. Human bone marrow-derived mesenchymal stem cells suppress human glioma growth through inhibition of angiogenesis. Stem Cells 2013; 31: 146-55.

[64] Zhang, A., Guan, Y., Chen, L. Stem cell delivery of anti-neoplastic medicine. US20100055167 (2010).

[65] Janes, S.M., Lythgoe, M.F., Pankhurst, Q. Use of nanoparticles for the treatment of cancer. US20120010499 (2012).

[66] Deng, W.-P., Chang, H.-K., Wei, H.-C., Wu, T.-H.A. Combination of protein vaccine and mesenchymal stem cells for treating cancer. US20110027311 (2011).

[67] Wei HJ, Wu AT, Hsu CH, Lin YP, Cheng WF, Su CH, et al. The development of a novel cancer immunotherapeutic platform using tumor-targeting mesenchymal stem cells and a protein vaccine. Mol Ther 2011; 19: 2249-57.

[68] Cohen, S. Pharmaceutical compositions and methods for the treatment and prevention of cancer. US20130052272 (2013).

[69] Bourbeau D, Lau CJ, Jaime J, Koty Z, Zehntner SP, Lavoie G, et al. Improvement of antitumor activity by gene amplification with a replicating but nondisseminating adenovirus. Cancer Res 2007; 67: 3387-95.

[70] Bourbeau D, Lavoie G, Nalbantoglu J, Massie B. Suicide gene therapy with an adenovirus expressing the fusion gene CD::UPRT in human glioblastomas: Different sensitivities correlate with p53 status. J Gene Med 2004; 6: 1320-32.

[71] Nelson, P.J. Engineered mesenchymal stem cells and method of using same to treat tumors. WO2010119039 (2010) \& US20120087901 (2012).

[72] Snyder, E.Y., Aboody, K.S., Brown, A.B., Breakefield, X.O. Systemic gene delivery vehicles for the treatment of tumors. US20050019313 (2005). 
[73] Flax JD, Aurora S, Yang C, Simonin C, Wills AM, Billinghurst LL, et al. Engraftable human neural stem cells respond to developmental cues, replace neurons, and express foreign genes. Nat Biotechnol 1998; 16: 1033-9.

[74] Suh, H.-Y., Chang, D.-Y., Kim, S.-S., Yoo, S.-W., Lee, Y.-D. Use of mesenchymal stem cells genetically modified to express a suicide gene for treating a cancer. US20080241115 (2008).

[75] Cady, C., McAsey, M. Stem cell targeting of cancer, methods and compositions therefore. US20090117050 (2009).

[76] Pereboeva L, Komarova S, Mikheeva G, Krasnykh V, Curiel DT. Approaches to utilize mesenchymal progenitor cells as cellular vehicles. Stem Cells 2003; 21: 389-404.

[77] Boyan, B.D., Schwartz, Z., Lee, C.S.D., Leslie, S.K., Kinney, R.C. Protein delivery from stem cell microcarriers. WO2012071527 (2012).

[78] Peak, H.J. Adipose-derived stromal cells (ASC) as delivery tool for treatment of cancer. US20110027239 (2011).

[79] Studeny, M., Andreeff, M., Marini, F.C. Local production and/or delivery of anti-cancer agents by stromal cell precursors. US20040076622 (2004).

[80] Kidd S, Caldwell L, Dietrich M, Samudio I, Spaeth EL, Watson K, et al. Mesenchymal stromal cells alone or expressing interferonbeta suppress pancreatic tumors in vivo, an effect countered by anti-inflammatory treatment. Cytotherapy 2010; 12: 615-25.

[81] Grisendi G, Bussolari R, Cafarelli L, Petak I, Rasini V, Veronesi E, et al. Adipose-derived mesenchymal stem cells as stable source of tumor necrosis factor-related apoptosis-inducing ligand delivery for cancer therapy. Cancer Res 2010; 70: 3718-29.

[82] Sasportas LS, Kasmieh R, Wakimoto H, Hingtgen S, van de Water JA, Mohapatra G, et al. Assessment of therapeutic efficacy and fate of engineered human mesenchymal stem cells for cancer therapy. Proc Natl Acad Sci USA 2009; 106: 4822-7.

[83] Szegezdi E, O'Reilly A, Davy Y, Vawda R, Taylor DL, Murphy M, et al. Stem cells are resistant to TRAIL receptor-mediated apoptosis. J Cell Mol Med 2009; 13: 4409-14.

[84] Ashkenazi A. Directing cancer cells to self-destruct with proapoptotic receptor agonists. Nat Rev Drug Discov 2008; 7: 100112.

[85] Hotte SJ, Hirte HW, Chen EX, Siu LL, Le LH, Corey A, et al. A phase 1 study of mapatumumab (fully human monoclonal antibody to TRAIL-R1) in patients with advanced solid malignancies. Clin Cancer Res 2008; 14: 3450-5.

[86] Kim SM, Woo JS, Jeong CH, Ryu CH, Lim JY, Jeun SS. Effective combination therapy for malignant glioma with TRAIL-secreting mesenchymal stem cells and lipoxygenase inhibitor MK886. Cancer Res 2012; 72: 4807-17.

[87] Shah, K. Multimodal TRAIL molecules and uses in cellular therapies. WO2012106281 (2012).
[88] Zhu W, Xu W, Jiang R, Qian H, Chen M, Hu J, et al. Mesenchymal stem cells derived from bone marrow favor tumor cell growth in vivo. Exp Mol Pathol 2006; 80: 267-74.

[89] Yu JM, Jun ES, Bae YC, Jung JS. Mesenchymal stem cells derived from human adipose tissues favor tumor cell growth in vivo. Stem Cells Dev 2008; 17: 463-73

[90] Pasquet M, Golzio M, Mery E, Rafii A, Benabbou N, Mirshahi P, et al. Hospicells (ascites-derived stromal cells) promote tumorigenicity and angiogenesis. Int J Cancer 2010; 9: 2090-101.

[91] Roodhart JM, Daenen LG, Stigter EC, Prins HJ, Gerrits J, Houthuijzen JM, et al. Mesenchymal stem cells induce resistance to chemotherapy through the release of platinum-induced fatty acids. Cancer Cell 2011; 3: 370-83

[92] Hao M, Zhang L, An G, Meng H, Han Y, Xie Z, et al. Bone marrow stromal cells protect myeloma cells from bortezomib induced apoptosis by suppressing microRNA-15a expression. Leuk Lymphoma 2011; 9: 1787-94

[93] Jin L, Tabe Y, Konoplev S, Xu Y, Leysath CE, Lu H, et al. CXCR4 up-regulation by imatinib induces chronic myelogenous leukemia (CML) cell migration to bone marrow stroma and promotes survival of quiescent CML cells. Mol Cancer Ther 2008; 1 : 48-58.

[94] Castells M, Thibault B, Mery E, Golzio M, Pasquet M, Hennebelle I, et al. Ovarian ascites-derived Hospicells promote angiogenesis via activation of macrophages. Cancer Lett 2012; 326: 59-68.

[95] Castells M, Thibault B, Delord J-P, Couderc B. Implication of tumor microenvironment in chemoresistance: Tumor-associated stromal cells protect tumor cells from cell death. Int J Mol Sci 2012; 13: 9545-71

[96] Teng IW, Hou PC, Lee KD, Chu PY, Yeh KT, Jin VX, et al. Targeted methylation of two tumor suppressor genes is sufficient to transform mesenchymal stem cells into cancer stem/initiating cells. Cancer Res 2011; 13: 4653-63.

[97] Ciavarella S, Dominici M, Dammacco F, Silvestris F. Mesenchymal stem cells: A new promice in anticancer therapy. Stem Cell Dev 2011; 20: 1-10.

[98] Menon LG, Kelly K, Yang HW, Kim SK, Black PM, Carroll RS Human bone marrow-derived mesenchymal stromal cells expressing S-TRAIL as a cellular delivery vehicle for human glioma therapy. Stem Cells 2009; 27: 2320-30.

[99] Hong X, Miller C, Savant-Bhonsale S, Kalkanis SN. Antitumor treatment using interleukin-12-secreting marrow stromal cells in an invasive glioma model. Neurosurgery 2009; 64: 1139-47.

[100] Hanahan D, Coussens LM. Accessories to the crime: Functions of cells recruited to the tumor microenvironment. Cancer Cell 2012 3: 309-22. 